\title{
Correction to: The Effects of Race, Gender, and Gender-Typed Behavior on Children's Friendship Appraisals
}

\author{
Miao Qian ${ }^{1,2}$ (D) Yang Wang ${ }^{3} \cdot$ Wang Ivy Wong ${ }^{4,5} \cdot$ Genyue Fu $^{6} \cdot$ Bin Zuo $^{3} \cdot$ Doug P. VanderLaan $^{7}$
}

Published online: 2 January 2021

๑) Springer Science+Business Media, LLC, part of Springer Nature 2021

Correction to: Archives of Sexual Behavior https://doi.org/10.1007/s10508-020-01825-5

The funding information stated for Bin Zuo (BZ) in the Acknowledgements of this article as originally published was incorrect.

The correct information is: grants from the National Social Science Major Project of China (18ZDA331) and the National Nature Science Foundation of China (NSFC) (31571147) awarded to BZ.

The original article has been updated.

Publisher's Note Springer Nature remains neutral with regard to jurisdictional claims in published maps and institutional affiliations.

The original article can be found online at https://doi.org/10.1007/ s10508-020-01825-5.

Doug P. VanderLaan

doug.vanderlaan@utoronto.ca

1 Applied Psychology and Human Development, Ontario Institute for Studies in Education, University of Toronto, Toronto, ON, Canada

2 Present Address: Department of Psychology, Harvard University, Cambridge, MA, USA

3 School of Psychology, Center for Studies of Social Psychology, Central China Normal University, Wuhan, Hubei, China

4 Department of Psychology, University of Hong Kong, Pokfulam, Hong Kong, China

5 Present Address: Department of Psychology, The Chinese University of Hong Kong, Hong Kong, China

6 School of Education, Hangzhou Normal University, Hangzhou, Zhejiang, China

7 Department of Psychology, University of Toronto Mississauga, Room 4098, Deerfield Hall, 3359 Mississauga Road, Mississauga, ON L5L 1C6, Canada 